\title{
Total Phenolic Content and Antioxidant Activity of Chickpea (Cicer arietinum L.) as Affected by Soaking and Cooking Conditions
}

\author{
Aharon Segev ${ }^{1}$, Hana Badani ${ }^{1}$, Liel Galili ${ }^{1}$, Ran Hovav ${ }^{1}$, Yoram Kapulnik ${ }^{1}$, Ilan Shomer ${ }^{2}$, \\ Shmuel Galili ${ }^{1 *}$ \\ ${ }^{1}$ Agronomy and Natural Resources Department, Agricultural Research Organization, The Volcani Center, Bet Dagan, Israel; ${ }^{2}$ Food \\ Science Department, Agricultural Research Organization, The Volcani Center, Bet Dagan, Israel. \\ Email: *galilis@agri.gov.il
}

Received May $4^{\text {th }}, 2011$; revised July $13^{\text {th }}, 2011$; accepted July $20^{\text {th }}, 2011$.

\begin{abstract}
Chickpea lines with colored testa (seed coat) contain high levels of polyphenolic compounds that exhibit high levels of antioxidant activity. However, common processing procedures, such as soaking and cooking, may decrease the levels of these bioactive compounds and subsequent overall antioxidant activity. Here, the effects of soaking, cooking and steaming processes were examined in relation to total phenolic content (TPC), total flavonoid content (TFC) and ferric reducing ability of plasma antioxidant activity (FRAP AA) of colored chickpea seeds. All processing steps significantly reduced TPC, TFC and FRAP AA in all of the tested chickpea seeds. Nevertheless, soaking the seeds at room temperature (for $22 \mathrm{~h}$ ) resulted in a smaller decrease in TPC, TFC and FRAP AA than soaking at $60^{\circ} \mathrm{C}$ (for $2 \mathrm{~h}$ ). Moreover, steaming was superior to cooking in terms of conserving polyphenol and antioxidant activity. The observed reduction in TPC was mainly due to leaching of these compounds from the seed coat into the soaking or cooking water. Based on these results, we suggest that soaking at room temperature for $22 \mathrm{~h}$ followed by steaming for $1 \mathrm{~h}$ is the best method for retaining TPC, TFC and FRAP AA of colored chickpea.
\end{abstract}

Keywords: Colored Chickpea Seeds, FRAP, Processing, Total Phenolics, Total Flavonoids

\section{Introduction}

Chickpea (Cicer arietinum L.) is an annual grain legume (pulse crop) that is extensively cultivated for human consumption. Chickpea is cultivated throughout the world, including the Mediterranean basin, the Near East, Central and South Asia, East Africa, South and North America, and Australia. It is the second-most important pulse crop in the world (after dry bean), covering 15\% (10.2 million ha) of the area dedicated to pulse cultivation and accounting for $14 \%$ ( 7.9 million tons) of pulse production worldwide (FAOSTAT http://faostat.fao.org/default.aspx). In Israel, chickpea is the main pulse crop, pp. it is grown on about 6000 to 10,000 ha spread throughout the country. Chickpea seeds vary in size, shape and color [1]. Based on these variations, chickpea cultivars are classified into two categories, pp. kabuli and desi [2]. The kabuli-type seeds have a thin seed coat ranging in color from white to cream and a 100 -seed weight of 28 to $70 \mathrm{~g}$. Desi-type chickpea seeds have a thicker, irregularly sha- ped seed coat, which ranges in color from light tan to black, and a 100 -seed weight of not more than $28 \mathrm{~g}$.

Polyphenols are common constituents of foods of plant origin and are major antioxidants in the human diet. These compounds possess diverse biological properties which provide a number of benefits, including antioxidant, apoptotic, antiaging, anticarcinogenic and anti-inflammatory activities, cardiovascular protection, and improvement of endothelial function. Polyphenols also inhibit angiogenesis and cell-proliferation activity (reviewed by [3]). Dry legumes are a good source of bioactive polyphenols [4] and also contribute to polyphenol intake from other foods [5]. The antioxidant capacity [6] and the antimutagenic [7-10], apoptosis-related [11] and antiproliferative effects of legumes are associated with the presence of phenolic compounds $[12,13]$. The abundance of phenolic compounds in such legumes as the common bean (Phaseolus vulgaris) [9], faba (broad) bean (Vicia faba) $[14,15]$, beach pea (Lathyrus maritimus) [16], 
mung bean (Vigna radiata) [17], lentil (Lens culinaris) [18] and chickpea (Cicer arietinum) [19-22] implies that they may be significant food sources of active antioxidants.

The amounts of polyphenols, flavonoids and antioxidant activity vary greatly among different legumes [20, 23]. In previous studies with chickpea, for example, we found that isolated hulls from a colored chickpea line contain large amounts of polyphenols and flavonoid compounds that exhibit high levels of antioxidant activity [22]. On the other hand, common chickpea varieties with beige-colored seeds have low levels of total phenolic content (TPC), total flavonoid content (TFC) and antioxidant activity determined by ferric reducing ability of the plasma (FRAP AA) $[22,23]$. This variation in both seed coat color and antioxidant activity makes colored chickpea a strong potential model for studies of functional foods. Chickpea, similar to other legume seeds, must be soaked and/or cooked before consumption, a procedure that improves the flavor and palatability of the food product and increases its nutritional bioavailability by inactivating antinutritional factors [24]. However, it also decreases the levels of bioactive compounds and antioxidant activity of these foods, as has been shown for several seed legumes, including kabuli-type chickpea lines $[19,21]$. The objective of this study was to determine the effects of soaking and cooking conditions on levels of bioactive compounds (polyphenols and flavonoids) and antioxidant activity in vitro, in seed-coat and dehulled-seed fractions from different chickpea accessions with differently colored seeds. This was done to determine their respective potentials for use as functional foods.

\section{Materials and Methods}

\subsection{Plant Material}

Two desi lines (731 with black color and 668 with red color) and one kabuli line (cv. Zehavit, a commercial Israeli kabuli cultivar, with beige color) of chickpea were used in this study. All desi-type lines were purchased from the National Germplasm Resources Laboratory (USDA-ARS, Beltsville, MD, USA). Seeds of all these lines were produced in our laboratory.

\subsection{Soaking and Determination of Hydration Rate}

Samples ( $2 \mathrm{~g}$ seeds per sample) of each chickpea line were used to determine the effects of soaking time and temperature on TPC, TFC and FRAP AA. Seeds of each line were soaked at room temperature $\left(25^{\circ} \mathrm{C}\right)$ in about 10 $\mathrm{ml}$ of tap water in 20-ml glass vials for 2, 6 and $22 \mathrm{~h}$, or in a water bath at $60^{\circ} \mathrm{C}$ for 1,2 and $6 \mathrm{~h}$. The water absorption (moisture increase) of the initially dry legumes during the course of the soaking process was evaluated by measuring seed weight at each time point. A waterabsorption curve was constructed by plotting the increase in relative seed weight against time (dry seed weight was defined as 100\%). At each time point, three vials of each of the desi and kabuli lines were sampled. All samples were freeze-dried and stored at $4^{\circ} \mathrm{C}$ until use (usually between 1 and 2 days).

\subsection{Regular Cooking and Steaming}

Chickpea seeds were pre-soaked at room temperature for $22 \mathrm{~h}$ as described in the previous section (defined as 0 time of cooking). For the regular cooking treatment, soaked seeds were immersed in $15 \mathrm{ml}$ of fresh tap water. All vial contents were brought to a boil in a $2.5-\mathrm{L}$ pot containing $2 \mathrm{~L}$ of tap water. Samples were drawn at 60 , 90 and 120 min of boiling.

Steaming was performed in a VC1002 steam cooker (Tefal, France). After pre-soaking at room temperature for $22 \mathrm{~h}$, chickpea samples were placed in a plastic net on a tray inside the steam cooker covered with a lid and steamed over $1 \mathrm{~L}$ of boiling water under atmospheric pressure. Samples were drawn after 60, 90 and $120 \mathrm{~min}$. After regular cooking or steaming, seeds were drained and cooled to room temperature. All samples were freezedried and stored at $4^{\circ} \mathrm{C}$ until use (usually between 1 and 2 days).

\subsection{Extraction of TPC and TFC from Chickpea Samples}

Seed samples were ground to a fine powder in a Retsch MM301 grinder. A 0.1-g portion of the powder was extracted in a 2-ml microfuge tube with $1 \mathrm{ml}$ of $50 \%$ acetone, previously found to be the best extraction solvent [22]. Extracts were kept in the dark at $4^{\circ} \mathrm{C}$ until use (on the same day in most cases) for determination of TPC, TFC and FRAP AA. All extractions were performed in triplicate.

\subsection{Determination of TPC, TFC and Antioxidant Activity Levels}

TPC in whole chickpea seeds was determined on a dry matter basis using the Folin-Ciocalteu assay $[25,26]$ and TFC was determined using a colorimetric method [6] in $50-\mu 1$ extraction samples, as previously described [22]. The FRAP method was used to evaluate the antioxidant activity of chickpea extracts, by measuring the ferric reducing ability of plasma at low pH levels [27] as previously described [22]. 


\subsection{Statistical Analysis}

Analyses were performed in triplicate. The data were subjected to ANOVA using JMP (Version 5.0). Tukey HSD multiple-range tests were carried out to detect significant differences between lines and between treatments. A Pearson correlation test was conducted to determine the correlation among variables. Levels of significance were defined using $P \leq 0.05$.

\section{Results and Discussion}

\subsection{Effects of Soaking on TPC, TFC and FRAP AA}

Soaking chickpea seeds in water or alkali salts is a common cooking pretreatment that allows for shortened cooking times and reduced energy costs [28]. Some food companies soak chickpea seeds at an elevated temperature (i.e. $\left.60^{\circ} \mathrm{C}\right)$ instead of overnight $(16-22 \mathrm{~h})$ at room temperature, in order to further shorten both soaking and cooking times. Thus, we first examined the effects of the duration and temperature of the soaking step on hydration, TPC, TFC and FRAP AA of the chickpea seeds. The effect of soaking temperature on the hydration rate of chickpea seeds is shown in Figure 1. Increasing soaking temperature from room temperature to $60^{\circ} \mathrm{C}$ significantly reduced seed-hydration time (three- to six-fold), regardless of the chickpea line used.

The effects of soaking conditions on TPC, TFC and FRAP AA are shown in Figure 2. Significant differences $(p<0.05)$ were found among the different soaking treatments for both the desi and kabuli chickpea lines. In both desi chickpea lines (668 and 731), soaking at $60^{\circ} \mathrm{C}$

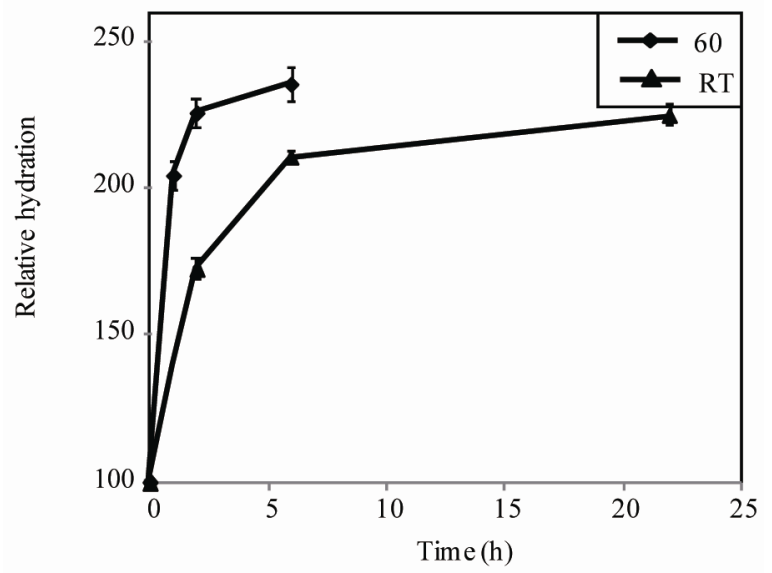

Figure 1. Water-absorption curve of chickpea seeds. Chickpea seeds were soaked at room temperature (RT) for 0 to 22 $h$ or at $60^{\circ} \mathrm{C}$ for 0 to $6 \mathrm{~h}$. Each curve represents the means \pm standard error of all three lines tested in this study. Dry seed weight was defined as $100 \%$. resulted in significantly greater reductions in TPC, TFC and FRAP AA than soaking at room temperature (Figures 2(a-f)). Temporally, when desi chickpeas were soaked at room temperature, significant reductions of $30 \%$ to $40 \%$ in TPC, TFC and FRAP AA occurred only after $22 \mathrm{~h}$ (Figures 2(a-f)). When these lines were soaked at $60^{\circ} \mathrm{C}$, however, significant reductions of up to $70 \%$ to $80 \%$ in TPC, TFC and FRAP AA were obtained after 1 to $6 \mathrm{~h}$ (Figures 2(a-f)). Analysis of the soaking water indicated that it contained about $85 \%$ of the lost TPC, and about $40 \%$ of the lost FRAP AA (data not shown). In the kabuli line (cv. Zehavit), there were small and in most cases nonsignificant reductions in TPC and TFC under room temperature soaking, and in FRAP AA under both soaking conditions (Figures 2(g-i)). However, soaking of this line at $60^{\circ} \mathrm{C}$ resulted in a significant (up to $45 \%$ ) reduction in TPC and a small nonsignificant increase in TFC (Figures 2(g-h)).

\subsection{Effects of Cooking on TPC, TFC and FRAP AA}

The effects of cooking method and duration are shown in Figure 3. Two cooking methods were examined, pp. regular cooking and steaming. Similar to the soaking treatments, both cooking methods resulted in significant reductions in TPC, TFC and FRAP AA in the desi-type lines (Figures 3(a-f)). Whereas regular cooking for 60 to 120 min caused significant (over 90\%) reductions in TPC, TFC and FRAP AA, steaming for 60 to 120 min caused significant reductions of only $70 \%$ to $80 \%$. Of these, about $110 \%$ of the lost TPC and about $55 \%$ of the FRAP AA were found in the cooking water (data not shown). The increase in TPC might have been due to the cooking process also releasing bound polyphenol. Similar reductions in TPC (up to 85\%) in regular cooking and in FRAP AA (up to $88 \%$ ) in both cooking methods were observed for the kabuli-type 'Zehavit' seeds (Figures 3(g-h)). No reduction in TPC was obtained during steaming, and as in soaking at $60^{\circ} \mathrm{C}$ (Figure 3(g)), a small nonsignificant increase in TFC was observed for both cooking methods (Figure 3(h)).

The levels of TPC, TFC and FRAP AA observed in this study for the dried seeds of the beige and the two colored chickpea lines were similar to our previous study [22] and to those obtained for yellow and black soybean [29]. As in our previous study [22], dried colored chickpea lines contained significantly higher levels of TPC, TFC and FRAP AA. Our results show that raw, colored chickpea has more FRAP AA than nuts, other seed legumes, mint, parsley and some dry fruits [30,23], and this property could determine the utility of these chickpeas as a functional food. However, this situation changes fol- 

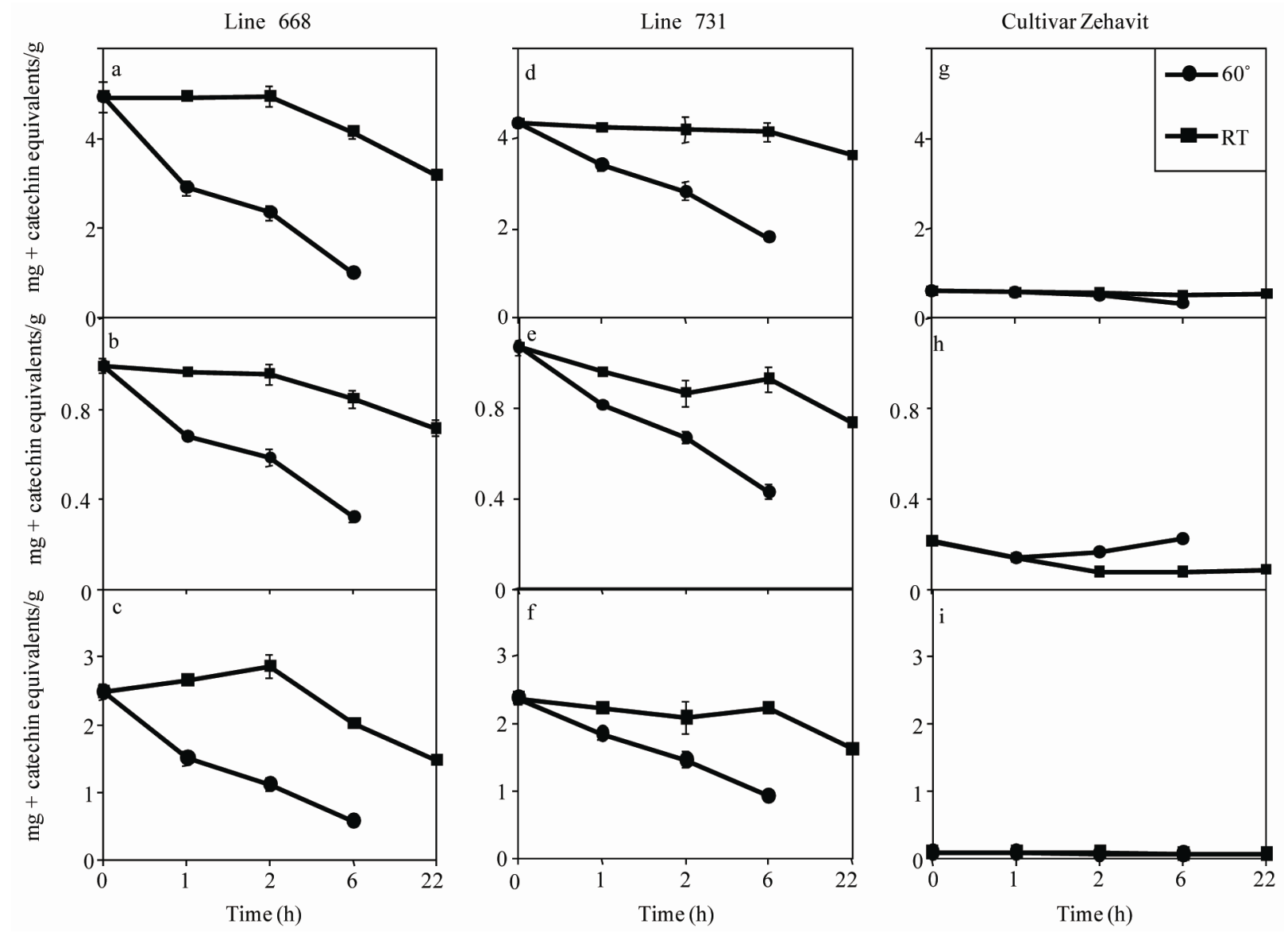

Figure 2. Effects of soaking on total phenolic content, total flavonoid content and antioxidant activity measured by the FRAP assay in chickpea seeds. Seeds of red desi line 668 (a-c), black desi line 731 (d-f) and beige kabuli cv. Zehavit (g-i) were soaked at room temperature (RT) for 0 (dried seeds) to $22 \mathrm{~h}$ or at $60^{\circ} \mathrm{C}$ for 0 to $6 \mathrm{~h}$. Total phenolic content is presented as mg + catechin equivalents/g dry seed. Each point represents mean \pm standard error of at least three replicates.

lowing processing, due to the fact that up to $95 \%$ of the TPC, TFC and FRAP AA are lost to the soaking and cooking water. Thus, after cooking, the levels of TPC, TFC and FRAP AA in colored chickpea seeds resembled those of the beige-colored seed. This phenomenon of decreasing TPC, TFC and FRAP AA during processing has also been observed for other seed legumes, including chickpea. Our results are similar to those observed for kabuli-type seeds [21], but differ from those for desi-type seeds [31]. Bressani and Elias [32] observed that about $40 \%$ of phenolics could be removed from common beans $(P$. vulgaris) by cooking and discarding the cooking water. Xu and Chang [29] found that most TPC, TFC and FRAP AA in black soybean are lost during cooking. Regular cooking caused greater TPC and TFC losses than steaming treatments, which could be attributed to water-soluble phenolics leaching into the soaking and cooking water $[21,29]$. In yellow soybean, similar to cv. Zehavit in this study, only a small decrease in TPC was found in both regular cooking and steaming; FRAP AA decreased significantly only during regular cooking, and TFC increased in both regular cooking and steaming [29]. The latter increase might be related to the release of phenolic or phenolic analogue polymerized structural substances such as lignin [29]. Cooking mung bean for $30 \mathrm{~min}$ resulted in a $73 \%$ reduction in polyphenols [33]. In the common bean, pressure cooking has been shown to enhance the diffusion of more than $90 \%$ of the polyphenols from seed coats to cooking water [34]. As shown in this study, soaking, cooking and steaming processes reduced TPC, TFC and FRAP AA in colored chickpea. This reduction might also affect the beneficial biological effects associated with these compounds. Thus, in order to maximize the nutritional value of chickpeas, new processing techniques that will restore the TPC, TFC and FRAP AA to the seed at the end of the processing procedure should be developed. One possibility is to minimize the volume of water used for soaking and reuse 

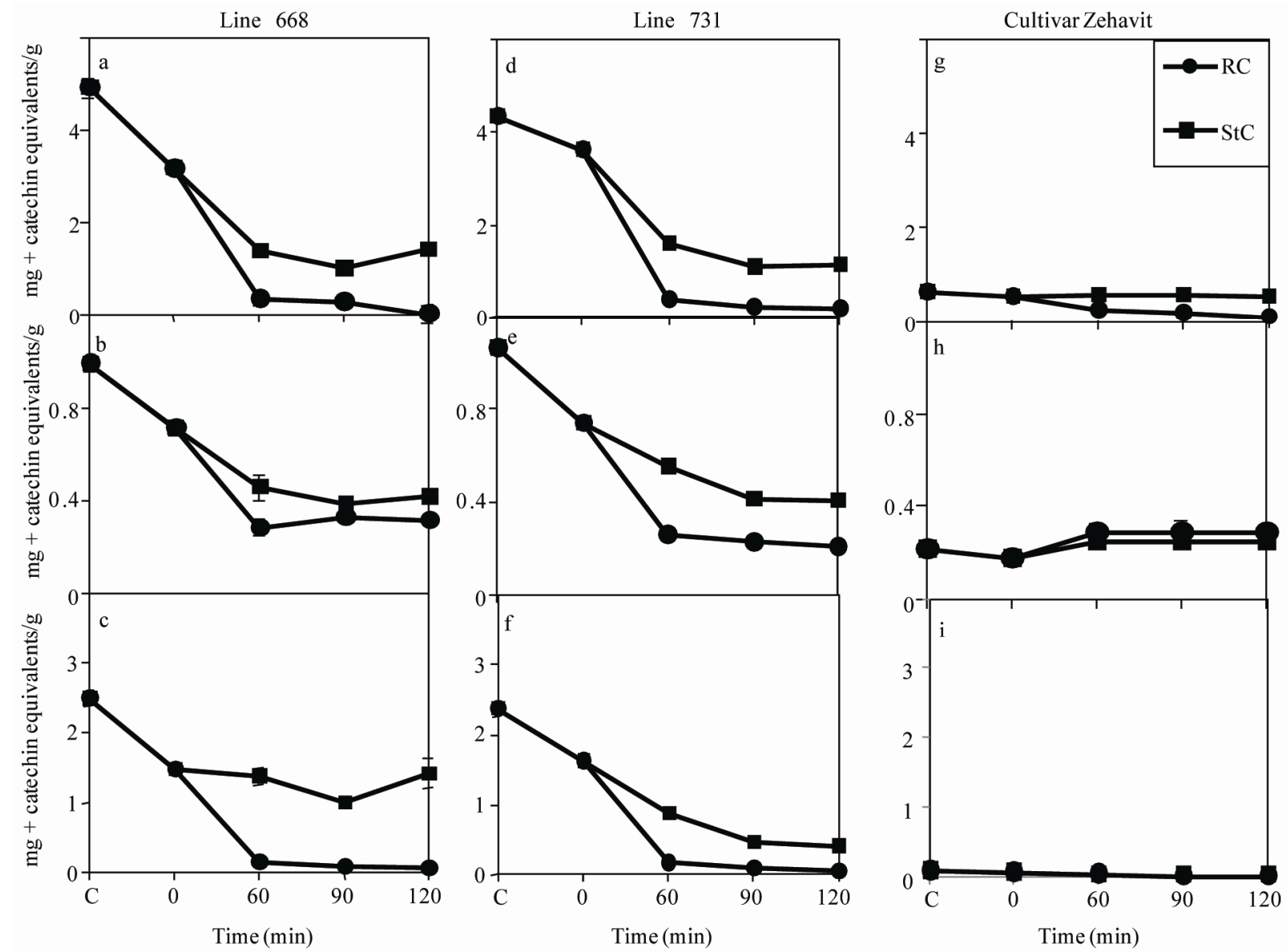

Figure 3. Effects of regular cooking (RC) and steaming (StC) on total phenolic content, total flavonoid content and antioxidant activity measured by the FRAP assay in chickpea seeds. Seeds of red desi line 668 (a-c), black desi line 731 (d-f) and beige kabuli cv. Zehavit (g-i) were soaked at room temperature (RT) for 22 h (time 0 ) followed by regular cooking or steaming for 60, 90 or $120 \mathrm{~min}$. Time (0) represents total phenolic content in dried seeds. Total phenolic content is represented as mg + catechin equivalents/g dry seed. Each point represents mean \pm standard error of at least three replicates.

soaking and cooking water. Indeed, using this method in the preparation of humus (a chickpea dish), we were able to retain TPC, TFC and FRAP AA in the end product (Galili, unpublished data).

\section{Conclusions}

We found that colored chickpea lines contain high levels of phenolic material that exhibits high levels of antioxidant activity. However, soaking, cooking and steaming processes significantly affected the TPC and antioxidant activities of all of the chickpea lines tested. The observed reduction in TPC was due to the movement of polyphenols from the seed coat to the soaking or cooking water. Steaming was found to be better than regular cooking in terms of conserving polyphenols. Based on these results, the use of soaking at room temperature for $22 \mathrm{~h}$ in combination with steaming for $1 \mathrm{~h}$ is suggested to be the best way to retain the TPC, TFC and FRAP AA of colored chickpea.

\section{REFERENCES}

[1] U. Singh, N. Subrahmanyam and J. Kumar, "Cooking Quality and Nutritional Attributes of Some Newly Developed Cultivars of Chickpea (Cicer arietinum)," Journal Science Food and Agriculture, Vol. 55, 1991, pp. 3746. doi:10.1002/jsfa. 2740550106

[2] B. Nizakat, B. K. Amal, S. S. K Gul, M. Zahid and I. Ihsanullah, "Quality and Consumer Acceptability Studies and Their Inter-Relationship of Newly Evolved Desi Type Chickpea Genotypes (Cicer arietinum L.). Quality Evolution of New Chickpea Genotypes," International Journal of Food Science and Technology, Vol. 42, 2007, pp. 528-534. doi:10.1111/j.1365-2621.2006.01246.x

[3] X. Han, T. Shen and H. Lou, "Dietary Polyphenols and Their Biological Significance," International Journal 
Molecular Science, Vol. 8, No. 9, 2007 pp. 950-988. doi:10.3390/i8090950

[4] P. B. Geil, and J. W. Anderson, "Nutrition and Health Implications of Dry Beans: A Review," Journal of the American College of Nutrition, Vol. 13, No. 6, 1994, pp. 549- 558.

[5] A. Scalbert, C. Manach and C. Morand, "Dietary Polyphenols and the Prevention of Diseases," Critical Reviews in Food Science and Nutrition, Vol. 45, No. 4, 2005, pp. 287- 306. doi:10.1080/1040869059096

[6] D. Heimler, P. Vignolini, M. G. Dini and A. Romani, "Rapid Tests to Assess the Antioxidant Activity of Phaseolus vulgaris L. Dry Beans," Journal of Agricultural and Food Chemistry, Vol. 53, 2005 pp. 3053-3056. doi:10.1021/jf049001r

[7] L. Azevedo, J. C. Gomes, P. C. Stringheta, A. M. M. C. Gontijo, C. R. Padovani, L. R. Ribeiro and D. M. F. Salvadori, "Black Bean (Phaseolus vulgaris L.) as Protective Agent against DNA Damage in Mice," Food and Chemical Toxicology, Vol. 41, No. 12, 2003, pp. 1671-1676. doi:10.1016/S0278-6915(03)00173-X

[8] A. Cardador-Martínez, A. Albores, M. Bah, V. CalderónSalinas, E. Castaño-Tostado, R. Guevara-González, A. Shimada-Miyasaka and G. Loarca-Piña, "Relationship among Antimutagenic Antioxidant and Enzymatic Activities of Methanolic Extract from Common Beans (Phaseolus vulgaris L.)," Plant Foods for Human Nutrition, Vol. 61, No. 4, 2006, pp. 161-168.

doi:10.1007/s11130-006-0026-4

[9] A. Cardador-Martinez, G. Loacra-Pina and B. D. Oomah, "Antioxidant Activity in Common Beans (Phaseolus vulgaris L.),"Journal of Agricultural and Food Chemistry, Vol. 50, No. 24, 2002, pp. 6975-6980. doi:10.1021/if020296n

[10] E. G. de Mejía, E. Castaño-Tostado and G. Loarca-Piña, "Antimutagenic Effects of Natural Phenolic Compounds in Beans," Mutation Research-Genetic Toxicology and Environmental Mutagenesis, Vol. 441, No. 1, 1999, pp. 1-9. doi:10.1016/S1383-5718(99)00040-6

[11] X. Aparicio-Fernández, R. Reynoso-Camacho, E. Castaño-Tostado, T. García-Gasca, E. González de Mejía, S. Guzmán-Maldonado, G. Elizondo, G. G. Yousef, M. A. Lila and G. Loarca-Piña, "Antiradical Capacity and Induction of Apoptosis in HeLa Cells by a Phaseolus vulgaris Extract," Plant Foods for Human Nutrition, Vol. 63 , 2008, pp. 35-40. doi:10.1007/s11130-007-0066-4

[12] X. Aparicio-Fernandez, T. Garcia-Gasca, G. G. Yousef, M. A. Lila, E. Gonzalez de Mejia and G. Loarca-Pina. "Chemopreventive Activity of Polyphenolics from Black Jamapa Bean (Phaseolus vulgaris L.) on HeLa HaCaT Cells," Journal of Agricultural and Food Chemistry, Vol. 54, 2006, pp. 2116-2122. doi:10.1021/jf052974m

[13] M. Dong, X. He and R. H. Liu, "Phytochemicals of Black Bean Seed Coats: Isolation, Structure Elucidation and Their Antiproliferative and Antioxidative Activities," Journal of Agricultural and Food Chemistry, Vol. 55, No. 15, pp. 2007, pp. 6044-6051.
[14] R. Amarowicz and B. Raab, "Antioxidative Activity of Leguminous Seed Extracts Evaluated by Chemiluminescence Methods," Zeitschrift fur Naturforschung, Vol. 52, 1997, pp. 709-712.

[15] M. Carbonaro, F. Virgili and E. Carnovale, "Evidence for Protein-Tannin Interaction in Legumes, Implications in the Antioxidant Properties of Faba Bean Tannins," Lebensmittel-Wissenschaft und Technologie, Vol. 29, 1996, pp. 743-750.

[16] F. Shahidi, U. D. Chavan, M. Naczk and R. Amarowicz, "Nutrient Distribution and Phenolic Antioxidants in AirClassified Fractions of Beach Pea (Lathyrus maritimus L.)," Journal of Agricultural and Food Chemistry, Vol. 49, 2001, pp. 926-933. doi:10.1021/jf0005317

[17] P. D. Duh, W. J. Yen, P. C. Du and G. C. Yen, "Antioxidant Activity of Mung Bean Hulls," Journal of the American Oil Chemists Society, Vol. 74, No. 9, 1997, pp. 10591063. doi:10.1007/s11746-997-0025-0

[18] R. Amarowicz, M. Karamac and U. Chavan, "Influence of the Extraction Procedure on the Antioxidative Activity of Lentil Seed Extracts in a b-Carotene-Linoleate Model System," Grasasy Aceites, Vol. 52, 2001, pp. 89-93. doi:10.3989/gya.2001.v52.i2.378

[19] H. Han and B.-K. Baik, "Antioxidant Activity and Phenolic Content of Lentils (Lens culinaris), Chickpeas (Cicer arietinum L.), Peas (Pisum sativum L.) and Soybeans (Glycine max) and Their Quantitative Changes during Processing," International Journal Food Science Technology, Vol. 43, 2008, pp. 1971-1978. doi:10.1111/j.1365-2621.2008.01800.x

[20] B. J. Xu and S. K. C. Chang, "A Comparative Study on Phenolic Profiles and Antioxidant Activities of Legumes as Affected by Extraction Solvents," Journal Food Science, Vol. 72, No. 2, 2007, pp. S159-S166. doi:10.1111/j.1750-3841.2006.00260.x

[21] B. Xu and S. K. C. Chang, "Effect of Soaking, Boiling and Steaming on Total Phenolic Content and Antioxidant Activities of Cool Season Food Legumes," Food Chemistry, Vol. 110, 2008, pp. 1-13.

[22] A. Segev, H. Badani, Y. Kapulnik, I. Shomer, M. OrenShamir and S. Galili, "Determination of Polyphenols, Flavonoids and Antioxidant Capacity in Colored Chickpea (Cicer arietinum L.)," Journal Food Science, Vol. 75, 2010, pp. S115-S119. doi:10.1111/j.1750-3841.2009.01477.x

[23] B. J. Xu, S. H. Yuan and S. K. C. Chang, "Comparative Analyses of Phenolic Composition, Antioxidant Capacity and Color of Cool Season Legumes and Other Selected Food Legumes," Journal Food Science, Vol. 72, 2007, pp. S167-S177. doi:10.1111/j.1750-3841.2006.00261.x

[24] C. F. Chau, P.C. Cheung, Y. S. Wong "Effect of Cooking on Content of Amino Acids and Antinutrients in Three Chinese Indigenous Legume Seeds," Journal of the Science of Food and Agriculture, Vol. 75, 1997, pp. 447-452. doi:10.1002/(SICI) 1097-0010(199712)75:4<447::AID-JS FA896>3.0.CO;2-5 
[25] V. L. Singleton, R. Orthofer and R. M. Lamuela-RavenTos, "Analysis of Total Phenols and Other Oxidation Substrates and Antioxidants by Means of Folin-Ciocalteu Reagent," Methods in Enzymology, Vol. 299, 1999, pp. 152-178. doi:10.1016/S0076-6879(99)99017-1

[26] V. L. Singleton and J. A. Rossi, "Colorimetry of Total Phenolic with Phosphomolybdicphosphotungstic Acid Reagents," American Journal of Enology and Viticulture, Vol. 16, No. 1, 1965, pp. 144-158.

[27] I. F. F. Benzie and J. J. Strain, "The Ferric Reducing Ability of Plasma (FRAP) as a Measure of "Atioxidant Power': The FRAP Assay," Analytical Biochemistry, Vol. 239, 1996, pp. 70-76. doi:10.1006/abio.1996.0292

[28] Y. Coskuner and E. Karababa, "Effect of Location and Soaking Treatments on the Cooking Quality of Some Chickpea Breeding Lines," International Journal of Food Science and Technology, Vol. 38, 2003, pp. 751-757. doi:10.1046/j.1365-2621.2003.00727.x

[29] B. Xu and S. C. Chang, "Total Phenolics, Phenolic Acids, Isoflavones and Anthocyanins and Antioxidant Properties of Yellow and Black Soybeans as Affected by Thermal Processing," Journal of Agricultural and Food Chemistry, Vol. 56, 2008b, pp. 7165-7175. doi:10.1021/jf8012234

[30] N. Pellegrini, M. Serafini, S. Salvatore, D. del Rio, M. Bianchi and F. Brighenti, "Total Antioxidant Capacity of
Spices, Dried Fruits, Nuts, Pulses, Cereals and Sweets Consumed in Italy Assessed by Three Different in Vitro Assays," Molecular Nutrition and Food Research, Vol. 50, 2006, pp. 1030-1038. doi:10.1002/mnfr.200600067

[31] S. B. Jood, M. Chauhan and A. C. Kapoor, "Polyphenols of Chickpea and Black Gram as Affected by Domestic Processing and Cooking Methods," Journal of the Science of Food and Agriculture, Vol. 39, 1987, pp. 145149. doi:10.1002/jsfa. 2740390207

[32] A. Bressani and L. G. Elias, "The Nutritional Role of Polyphenols in Beans," In: J. H. Hulse Ed., Polyphenols in Cereal and Legumes, International Development Research Center, Ottawa, Canada, 1980, pp 61-68.

[33] C. F. Barroga, A. C. Laurena and E. M. T. Mendoza, "Polyphenols in Mung Bean (Vigna radiata (L.) Wilczek). Determination and Removal," Journal of Agricultural and Food Chemistry, Vol. 33, 1985, pp. 1006-1009. doi:10.1021/jf00065a056

[34] N. E. Rocha-Guzman, R. F. Gonzalez-Laredo, F. J. Ibarra-Perez, C. A. Nava-Berumen and J.-A. GallegosInfante, "Effect of Pressure Cooking on the Antioxidant Activity of Extracts from Three Common Bean (Phaseolus vulgaris L.) Cultivars," Food Chemistry, Vol. 100, 2007, pp. 31-35. doi:10.1016/j.foodchem.2005.09.005 